\title{
On trekking to operant frontiers
}

\author{
DAVID A. CASE \\ University of Califormia, San Diego, La Jolla, Califormia
}

\begin{abstract}
Only recently have psychologists begun to explore systematically the unmapped territory of validating numerous, detailed operant principles in nonclinical human populations. Several concerns question the usefulness of simplistic leverpressing tasks superficially patterned on nonhuman laboratory studies. A realistic uniform laboratory context for responding would help address some of them. Research conducted by my colleagues and me using the Star Trek computer game is proffered as an exemplar.
\end{abstract}

Psychological research in the operant tradition (see Harzem \& Zeiler, 1981; Honig, 1966; Honig \& Staddon, 1977; and Iverson \& Lattal, 1991, for edited volumes of periodic reviews of the current literature) began with the study of nonhumans in laboratories (Skinner, 1938). Though these "Skinner Box" methods were notably artificial, the elimination of extraneous influences and the modification of unrestrained subjects' common behaviors with positive reinforcement were unusually successful. The basic principles that emerged held promise of utility and wide generality, and they were applied almost immediately to some of the most problematic conduct of humans, including autistic, retarded, and self-injurious behavior, which had previously been inadequately responsive to nonoperant therapies (Catania \& Brigham, 1978; Kazdin, 1994; Schreibman, 1988; Ullman \& Krasner, 1965).

To a first approximation, these increasingly effective applications validated the principles. But the main justification was to provide better help to severely needy people as quickly as was permitted by an emerging science. This history of operant psychology left a significant territory unmapped that only recently has begun to be thoroughly explored: the testing of the validity of the basic principles in nonclinical populations (Buskist \& Miller, 1982; Davey \& Cullen, 1988). Ideally such testing begins under laboratory conditions before being extended to a risky real world.

Tardiness in the systematic study of typical human conduct from this perspective ironically derives from the enormous influence of the founding father of the operant tradition, B. F. Skinner. Skinner was simply too busy with other matters to undertake this empirical research himself. He was not content to wait for it, though, arguing rather that his own and others' similar conduct could begin to be interpreted and influenced by generalizing

Research and manuscript preparation supported by NIMH Grant MH-20752 and NSF Grant IBN94-07206 to the University of California, San Diego. Edmund Fantino is the principle investigator for these awards. Reprints, software, and game documentation may be obtained from the author at the Department of Psychology, 0109, University of California, San Diego, 9500 Gilman Drive, La Jolla, CA 92093-0109. from the artificial, nonhuman laboratory precedent (Skinner, 1953, 1957, 1969). The problem with this strategy was that skeptics might not be persuaded by armchair speculations and the parallels that Skinner drew (e.g., Chomsky, 1959), nor should they easily be so. Skinner tended blithely to define away many of the common sorts of complexities that can crop up in everyday contexts. Some promising tentative inquiries were made by others (e.g., Weiner, 1962, 1983). These researchers sought to copy-perhaps somewhat superficially-the leverpressing tasks that worked so well with nonhumans for hundreds of researchers following in Skinner's footsteps.

Several concerns about these tasks have been raised, however. Aside from presenting instructions, one cannot establish motivation for responding remotely so easily with humans as with nonhumans. Given the demands of a particular experimental task, human subjects therefore typically have had little at stake should their performances not be even approximately optimal. Extreme schedule insensitivity is a common result (Baron \& Galizio, 1983; Mathews, Shimoff, Catania, \& Sagvolden, 1977). Also, the prototypical procedure - leverpressing on command for small amounts of money presented according to circumscribed intermittent schedules of reinforcement - may not be that realistic. Though undoubtedly reinforcing, money in leverpressing tasks is a type of reinforcer that usually cannot be utilized until another time. This may require severe qualification of conclusions in comparison with those made about the effects of immediately consumable reinforcers of the type that, with the exception of token economies, have virtually always been used in validations of the operant principles with clinical populations. Monetary reinforcement in the real world may not correspond very well to laboratory usage of it.

Perhaps more important, in contrast with nonhuman subjects, humans generally (but adults especially) bring with them into the laboratory extensive histories in a wide variety of contexts, most notably a vast verbal repertoire. The contemporary extralaboratory context of subjects also is typically unknown and is presumably variable even across similar individuals. A possible way to control for such variability would be to use a realistic 
uniform laboratory context for responding. That is, a sufficiently compelling laboratory context might isolate target responding from extraneous variables, which would be not unlike conducting a chemistry experiment in a test tube.

The remainder of the present report summarizes recent research that my colleagues and I (Case, Lattal, \& Fantino, 1994; Case, Ploog, \& Fantino, 1990; Lattal, Case, \& Fantino, 1994) have conducted with computer games. It is offered as an exemplar for how the objective of validating operant principles in nonclinical populations might be approached differently, perhaps in an improved fashion. One component of this proffered demonstration is the exploitation for scientific ends of a relatively advanced software technology that was originally intended for commercial entertainment purposes. This computer game project also illustrates the use of games as contexts for arranging contingencies of reinforcement that are well integrated into the "experimental task." This is to be contrasted with (1) using the opportunity to play computer games as a rewarding consequence for some sort of extraneous required activity, and (2) making an originally seriously minded task into a game.

The original class of procedures that we investigated concerns what is called observing behavior. Observing responses are explicit attentional responses that are maintained by informative properties of stimuli (Dinsmoor, 1983; Wyckoff, 1952). The game that we utilized and the seminal research that we conducted with it will be described momentarily. But first it is worth noting that we extensively evaluated several varieties of existing computer games in search of the one most readily adapted to the specific research realm of observing behavior. Among adventure or role-playing (e.g., Dungeons and Dragons), arcade (e.g., Missile Command), simulation (e.g., Flight Simulator), and originally nonmechanical (e.g., ping pong as in Little Brick Out; playground tag as in Donkey Kong; games of chance and betting such as poker; complex infinitely variable games such as chess) games, we determined that a popular computer game called Star Trek would likely be well suited. It contained identifiable reinforcing stimuli for clearly structuring playing strategy (discovery and destruction of enemy Klingon invaders) and, more importantly, a variety of well-integrated informative stimuli. The game was also a relatively credible simulation of reality, with about 20 concurrently available responses (called "commands") and nearly innumerable graphic, sound, and verbal stimuli serving as either consequences or discriminative stimuli. One final critical feature of this selection as opposed to the many vying candidates was our access to the source code in BASIC computer language, so that the necessary experimental contingencies, copied essentially identically from nonhuman research, could be inserted and manipulated.

Star Trek turned out to be a fortuitous choice. The television show on which the game was patterned was unusually successful. Subsequent to our adoption of the game, several extensions of the same general theme have been equally or more successful, as is manifested, for example, in popular movies and other television shows, books, memorabilia, enthusiast conventions, and even additions to the common vernacular (e.g., "warp speed"). Purportedly Star Trek is the first game to have been programmed on computers that did not exist prior to computers (originally, back in the 1960s, and somewhat incredibly in the context of present-day computer hardware, played on Teletype machines). It is probably wise of researchers to capitalize on such extraneous notoriety, perhaps more so when attempting to use a game as an experimental apparatus and general procedure.

\section{Description of the Original Star Trek Game}

The scenario of Star Trek involves the "Federation being attacked by a deadly Klingon invasion force.... As commander of the United Starship Enterprise, it is your [i.e., a subject's] mission to destroy this invasion force." Figure 1 shows a drawing of the monitor with a typical display, shortly after the beginning of a game and before discovery of any Klingons. An $8 \times 8$ matrix of quadrants constitutes the entire (two-dimensional) universe (not illustrated). Each quadrant consists of a $10 \times 10$ matrix of positions called sectors. Displayed in the upper left portion of the monitor is the immediate quadrant, which is the one currently occupied by the Enterprise (whose within-quadrant position is shown graphically by the letter E; stars are shown with asterisks; starbases, not shown in the figure, with the letter B; and Klingons, with the letter $\mathrm{K}$ ). The upper right portion contains information on the current status of the game, and the lower half of the screen is used for entering commands and for displaying messages to the captain (or commander-i.e., the subject). The bottom portion scrolls up with each new line as in typical monitor use. Commands are entered by typing two mnemonic letters. These are shown in Figure 1 for one version of the game, not including the command $\mathrm{CO}$ which lists the commands and their abbreviations. Some commands require additional input; MO (move), for example, needs direction and distance specifications (see the bottom of Figure 1).

\section{How Star Trek Was Modified for Observing Behavior Research}

The original version of the game was simplified by eliminating (1) a number of relatively exotic commands (such as an unpredictable and hazardous experimental death ray weapon and a command to abandon ship for a lifeboat-like craft) that typically were seldom used, and (2) the more powerful commander enemy spaceships, thereby leaving just the one type of primary reinforcing event - destruction of enemy Klingons - to establish the primary objective of one's playing strategy. The schedule for Klingon attack was originally, in effect, a variableratio contingency (i.e., response-based discovery of Klingons independently of passage of time), which we changed to a variable-time schedule. In a variable-time schedule 


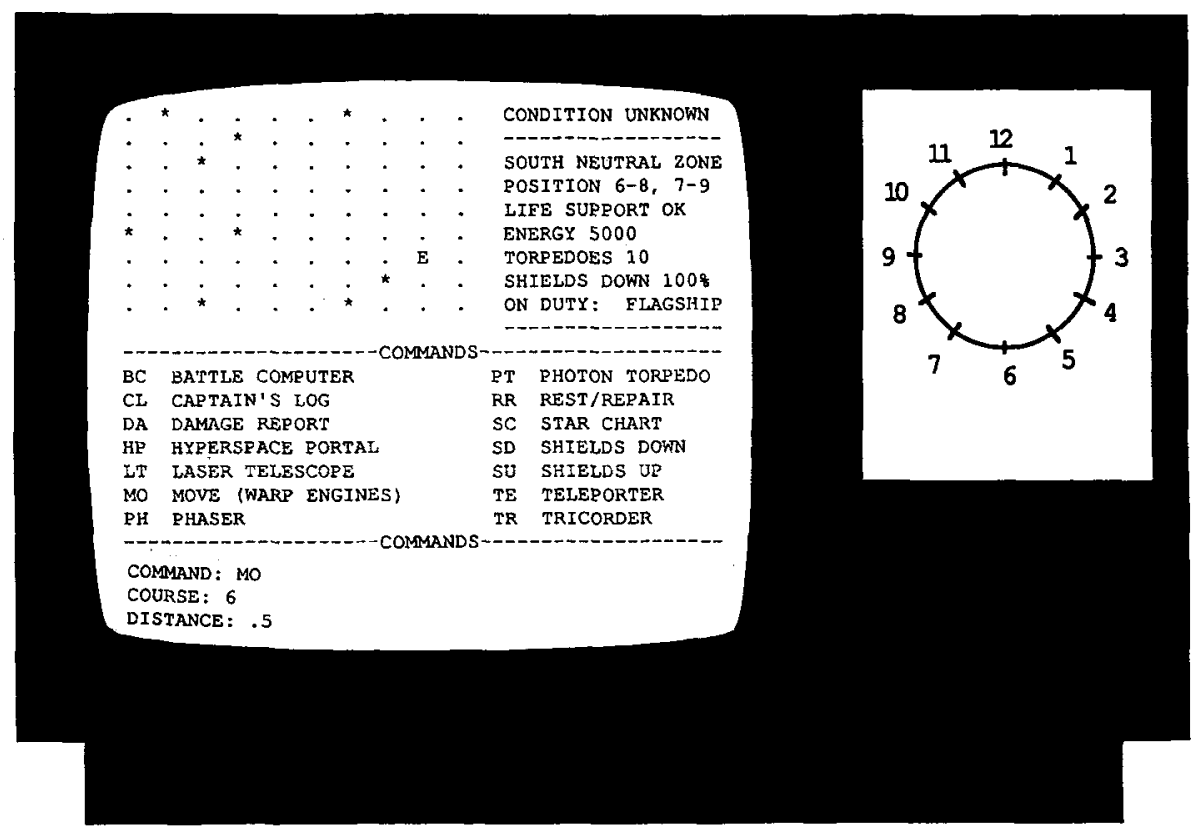

Figure 1. Illustration of computer monitor with typical Star Trek Display.

of reinforcement, an event occurs unpredictably after varying intervals since the last one, independently of any particular response of the subject. This schedule alternated with equal periods of a schedule of nonreinforcement-extinction.

In the absence of observing behavior, subjects had no cue to determine whether the variable-time or extinction component was currently operative. We introduced two observing response commands, thus providing a choice between response-contingent cues signaling the probability of encountering Klingons. In the original game, a status indicator in the upper right portion of the screen called the battle condition was green unless a Klingon was currently attacking the Enterprise, in which case it displayed red alert. We changed it to unknown in the absence of observing behavior, to red when an observing response changed the indicator during the Klingon component, and likewise to green during identified periods of extinction. As a control, in a second experimental condition, the battle status message could be changed by an observing response from unknown to yellow which was uncorrelated with the variable time and extinction components.

We named the observing response commands tricorder and $\mathrm{Mr}$. Spock (though we soon changed the latter to battle computer, because subjects were biased toward that name). The observing response commands were scheduled on a time-based variable schedule. When issuing one of these commands without producing an effect on the battle condition status, a message at the bottom said, "Not available at the moment--keep trying." These relatively complex and esoteric contingencies were the minimum necessary to prevent the absence of a stimulus change contingent upon an observing response from being as informative as the production of a battle condition stimulus.

\section{Observing Behavior Research With Star Trek}

Because primary reinforcement does not depend on observing behavior, the question of what maintains observing arises. One view holds that reduction in uncertainty is the critical factor; alternatively, it may be the association with primary reinforcement that the cues produced by observing might have. We found support for the latter over the former view, in that, first, the observing response command producing the Klingoncorrelated stimulus was preferred over the extinctioncorrelated stimulus. Second, the uncorrelated stimulus (battle condition yellow) was preferred over the extinctioncorrelated stimulus (green) under certain conditions and not others.

If the teleporter and the rest and repair commands were continuously available to use in preparing for subsequent battles, the extinction and control stimuli were observed about equally often. But if access to these commands was excluded during presentation of either observing-contingent stimulus, preference for the uncorrelated stimulus was obtained (no news was preferred over knowing there would be no Klingons to fight). That is, if the bad news of learning that no Klingons were currently available for possible discovery and destruction could be an advantage (e.g., by restocking supplies and repairing damage to the Enterprise), then the information actually was mixed and partially "good." This partial good news of the extinction-correlated stimulus permits a more efficient allocation of behavior than is 
otherwise permitted by the uncorrelated stimulus (during which there remained a possibility of a Klingon attack). When the news was more purely bad, that stimulus was not observed above the control rate of observing maintained by the uninformative stimulus, and it actually suppressed observing behavior similarly to the way in which the bad news was avoided relative to the good news of the Klingon-correlated stimulus. These conclusions agree with the overwhelming preponderance of evidence from human and nonhuman experiments (however, see Perone \& Kaminski, 1992, for conflicting data and an alternate perspective; and see Case et al., 1994, for an empirical reply to their challenge).

\section{A Second Substantive Application of Star Trek: Self-Control}

We have more recently attempted to apply this computer game methodology to the realm of self-control choice (Lattal et al., 1994). In operant psychology, selfcontrol is studied most often by arranging choices between alternate reinforcement schedules that differ in both the amount and delay of reinforcers. Specifically, a preferred reinforcer can be acquired only at the sacrifice of a greater delay in obtaining it following the choice. When this tradeoff results in predominant preference for a less valuable, immediate reinforcer, choice is said to be impulsive, the opposite of self-control. Subjects playing this version of Star Trek defend the Federation against two types of enemy invaders-Klingons and Romulans - which approach for attack through their respective bordering South and North Neutral Zones that flank Federation Space (Figure 2). Allocation of choice between these enemies - specifically, between these regions of the galaxy -is our measure of preference involving self-control.

The Klingons are described as an aggressive race, valuing their own destruction should it occur in the course of battle. Thus, this is the impulsive alternative that we engineered, and note that no delay need intervene between enemy attack and an Enterprise counterattack. By contrast, the Romulans are described as more technologically advanced, specifically possessing cloaking devices that permit them to attack without possibility of counterattack. That is, counter attack was not possible until the Enterprise is shifted into hyperspace (shown graphically with the inverse video display mode) by using the hyperspace portal command. Obviously, Romulans are the self-control alternative, because battle with them involves a delay of at least an extra required command. The sound and visual effects associated with destruction of Romulan spaceships also are more substantial and longer in duration than the Klingons'.

To make the procedure more sensitive for detecting effects of reinforcer delay, and also more efficient for studying self-control, we actually introduced two types of enemy Romulan starships, cruisers and flagships. They differ in the delay entailed in their counterattack by the Enterprise, measured from the time of encounter with each. The flagships are described as faster and are

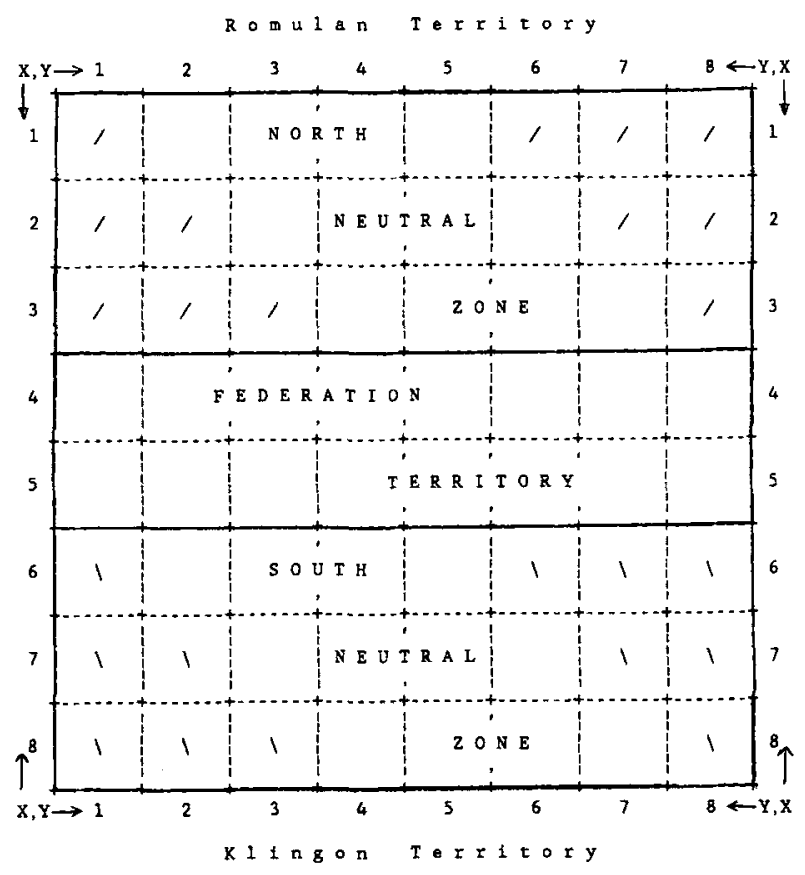

Figure 2. mlustration of regions into which the Star Trek universe is divided in the game versions used to study self-control and risksensitive choice.

programmed to flee the immediate quadrant as soon as hyperspace is entered. Cruisers merely move around randomly within the immediate quadrant, as the Klingons always do and as the Romulan flagships do once caught up to by the Enterprise. The different kinds of Romulan spaceships alternate across sessions every couple of minutes. This is indicated by a message in the lower half of the screen at the time of alternation, and the current type of Romulan ship that might attack at any moment is signaled continuously by a line in the status area in the upper right portion (e.g., On Duty: Flagship).

In summary, subjects were given two self-control choices alternately across time during each session, in each case involving the same impulsive Klingon enemy. Since the Romulan flagship self-control alternative involved a greater added delay than did the Romulan cruiser, the normative expectation was that choice should shift during the Flagship component toward the Neutral Zone through which Klingons approached, relative to choice in the cruiser component. An ideal result would be predominant self-control preference during the cruiser component (because of the relatively short self-control delay) and predominant impulsive preference during the flagship component (because of the relatively long selfcontrol delay).

Our results in this paradigm are a bit preliminary, but we think that they are sufficiently intriguing to justify their present discussion. We found that the self-control alternative was preferred in both components (i.e., at both delays). As with the observing behavior research described earlier, our data replicate prior studies not in- 
volving computer games (Logue, 1988). The data surprised us, nevertheless, given the general supposition that playing computer games involves relatively shortsighted motivations and may possibly lead to increased impulsivity across many hours of play (e.g., the suggestion made in the popular media that computer games can be "addicting" and can undermine the social development of children). However, our results did not replicate prior findings in another respect. Previously, researchers have found that the self-control preference among college students is eliminated if an additional contingency is used that requires that approximately equal numbers of impulsive and self-control reinforcers be obtained (Logue, King, Chavarro, \& Volpe, 1990). The same requirement was present in Star Trek throughout the experiment and, as stated, self-control preference was obtained. One speculation is that an element of "challenge" was involved that counteracted the reinforcer delay variable. We are presently exploring this possibility.

One of the main reasons for our studying self-control with Star Trek was the apparent contrast between humans' performance in the laboratory (strong self-control) as opposed to the real world, where even college students themselves will concede that they exhibit relatively routine impulsivity, as in going on a date or sleeping late rather than studying for an examination to be held the next day and attending all lectures. Of course, such inconsistency may be more apparent than it is real, since one of the things that makes college students stand apart from their peers is a willingness to learn more and earn less now in the hopes of earning more later. At any rate, there seems to be a clear difference between adults and nonhumans in self-control, which deserves particularly close investigation because of the implications for validating basic operant principles in the laboratory with nonclinical human subjects. One concern has been that with the typical reinforcer used-money-backed pointsthere is little reason for leaning toward immediate as opposed to delayed reinforcer acquisition within sessions, because the consummatory behavior permitted by the earned money cannot be engaged in until after sessions end. This is not the case in playing computer games, in which the reinforcers are integrated into the task. In this situation, what you see is all that you get, and there is no corresponding consummatory responding later on.

\section{Presently Ongoing Research With Star Trek: Risk-Sensitive Choice as a Function of Resource Budget}

Of all the parameters involving reinforcement contingencies, perhaps the most tricky to investigate is reinforcement variability, or risk, which people generally recognize as an incredibly pervasive issue in their lives. For this reason, the study of risk-sensitive choice by simulating real-world contexts in the laboratory is perhaps the most significant area of all for potential application of the present methodology. This situation is heightened in import because of recent findings with certain species of nonhumans that risky choices vary according to the budget rule (Caraco \& Lima, 1985). To wit, when resources are lean and survival is threatened, shifting toward risk (away from a certain alternative) may be adaptive, whereas a conservative strategy is probably more likely to succeed under balanced or positive budget conditions. This entirely plausible principle has not been easy to assess in humans with the use of typical methods, in part for the obvious reason that it is difficult to manipulate resource budgets in a meaningful way. However, in the context of Star Trek, this manipulation amounts to a trivial change in the program. For example, the number of photon torpedoes and the energy stores are either severely limited or made excessively abundant for the needs at hand. Similarly, success in defending the Federation from attack is arranged as a requirement for continued playing, sometimes with an added monetary incentive to play as long as possible. The analogy is to survival in real-world ecology. The choice in this, the third application of the game methodology, is between Klingons and Romulans which differ only in the degree of variability of their scheduling. One alternative is always constant; the other, always risky. Both variability in number of enemy invaders per encounter and variability in the delay to encounter an enemy following choice between Neutral Zones are being studied independently. Unfortunately, no preliminary results are available for description at this time.

\section{Qualifications and Implications}

Star Trek is not without its limitations. Superficially, the game seems a bit crude in comparison with many others invented more recently, especially in terms of high-resolution graphics and sounds. However, the greater tractability of Star Trek in terms of manipulation of reinforcement contingencies may make it more tenable as a method for experimental psychology than these ostensibly more advanced games. The popularity of the entire Star Trek phenomenon (movies, books, fan clubs, action figure toys, etc.) also gives the game an advantage over computer games with more esoteric origins and few if any elaborations in the wider popular culture.

For games truly to become a widely useful tool for the validation of operant principles in the laboratory, a large number of researchers will have to invest their time and resources over a considerable period. This raises the issue of developing a degree of standardization, lest such an effort be inexcusably inefficient. Standardization efforts should probably involve focusing on a relatively limited number of games - perhaps even just one very flexible game (and Star Trek may qualify as much as any other in this respect as herein illustrated)-and then abstracting core features for defining a common starting point from which any presently conceivable schedule of reinforcement may be derived. Of course, there will always be a tension between limiting the range of game variants in common use (for efficiency) and the essential point of the research enterprise, which is to stretch boundaries. 
Another conceivable way for operant research using games to evolve is to exploit additional existing software designed originally for commercial entertainment purposes. For example, Star Trek may be too difficult for very young children. At any rate, in this regard the foremost problems needing solution are related to getting access to source code while protecting game authors' legitimate income potential through copyright protection and royalties. In principle, there is no reason why such software cannot be used for nonprofit research purposes quite independently of commercial considerations. In fact, our experience is that a lot more trust in the integrity of scientists may be needed than has been necessary in the past, probably simply because there are often much greater financial stakes today.

In conclusion, trekking to operant frontiers as presently described has not meant going where no one has gone before. That would more appropriately describe the discovery of novel principles rather than the verification of previously proposed ones in a different-however important-population of subjects. Likewise, it is not justifiable to suggest that nonclinical human operant laboratory research is psychology's final frontier-the real world is, obviously. Nevertheless, my colleagues and I hope that the Star Trek game will become a " $\mathrm{Hu}$ man Skinner Box"- that is to say, a standardized general method from which an almost endless number of theoretically relevant variants may be easily derived. We call on other researchers intrigued by the accomplishments so far with Star Trek to help us make it so.

\section{REFERENCES}

Baron, A., \& Galizio, M. (1983). Instructional control of human operant behavior. Psychological Record, 33, 495-520.

Buskist, W., \& Miller, H. L. (1982). A study of human operant behavior, 1958-1981: A topical biography. Psychological Record, 32, 249-268.

CARACo, T., \& LiMA, S. L. (1985). Foraging juncos: Interaction of reward mean and variability. Animal Behaviour, 33, 216-224.

CAse, D. A., LatTal, K. M., \& Fantino, E. (1994). Bad news, mixed news, and multiple messages: Getting at truth about human observing behavior. Paper presented at the convention of the Association for Behavior Analysis, Atlanta.

Case, D. A., Ploog, B. O., \& Fantino, E. (1990). Observing behavior in a computer game. Journal of the Experimental Analysis of Behavior, 54, 185-199.

Catania, A. C., \& Brigham, T. A. (Eds.) (1978). Handbook of applied behavior analysis: Social and instructional processes. New York: Irvington.

Сномsкy, N. (1959). Review of B. F. Skinner's Verbal behavior. Language, 35, 26-58.

Davey, G., \& Cullen, C. (Eds.) (1988). Human operant conditioning and behavior modification. New York: Wiley.

DINSMOOR, J. A. (1983). Observing and conditioned reinforcement. Behavior \& Brain Sciences, 6, 693-728.

HARZEM, P., \& ZEILER, M. D. (Eds.) (1981). Advances in the analysis of behavior: Vol. 2. Predictability, correlation, and contiguity. New York: Wiley.

HoNIG, W. K. (Ed.) (1966). Handbook of operant behavior: Areas of research and application. New York: Appleton-Century-Crofts.

HoNiG, W. K., \& STADDON, J. E. R. (Eds.) (1977). Handbook of operant behavior. Englewood Cliffs, NJ: Prentice-Hall.

IVERSON, I. H., \& LATTAL, K. A. (Eds.) (1991). Experimental analysis of behavior. New York: Elsevier.

KAZDIN, A. E. (1994). Behavior modification in applied settings $(5$ th ed.). Pacific Grove, CA: Brooks-Cole.

LatTal, K. M., Case, D. A., \& Fantino, E. (1994). Self-control and impulsive choice in a computer game. Paper presented at the convention of the Association for Behavior Analysis, Atlanta.

Logue, A. W. (1988). Research on self-control: An integrating framework. Behavior \& Brain Sciences, 11, 665-679.

Logue, A. W., King, G. R., Chavarro, A., \& Volpe, J. A. (1990). Matching and maximizing in a self-control paradigm using human subjects. Learning \& Motivation, 21, 340-368.

Mathews, B. A., Shimofe, E. H., Catania, A. C., \& Sagvolden, T. (1977). Uninstructed human responding: Sensitivity to ratio and interval contingencies. Journal of the Experimental Analysis of Behavior, 27, 453-467.

Perone, M., \& Kaminski, B. J. (1992). Conditioned reinforcement of human observing behavior by descriptive and arbitrary verbal stimuli. Journal of the Experimental Analysis of Behavior, 58, 557-575.

Schreibman, L. (1988). Autism. Newbury Park, CA: Sage.

SKINNER, B. F. (1938). The behavior of organisms. New York: Appleton-Century-Crofts.

SKINNER, B. F. (1953). Control and analysis of human behavior. New York: Macmillan.

SkINNER, B. F. (1957). Verbal behavior. New York: Appleton-CenturyCrofts.

SKINNER, B. F. (1969). Beyond freedom and dignity. New York: Knopf.

Ullman, L. P., \& KRASNer, L. A. (1965). A psychological approach to abnormal behavior. Englewood Cliffs, NJ: Prentice-Hall.

WEINER, H. (1962). Some effects of response cost upon human fixedinterval operant behavior. Journal of the Experimental Analysis of Behavior, 5, 201-208.

WEINER, H. (1983). Some thoughts on discrepant human-animal performances under schedules of reinforcement. Psychological Review, 33, 521-532.

WYCKoFf, L. B., JR. (1952). The role of observing responses in discrimination learning: Part I. Psychological Review, 59, 431-442.

(Manuscript received November 21, 1994; revision accepted for publication January 27,1995 .) 